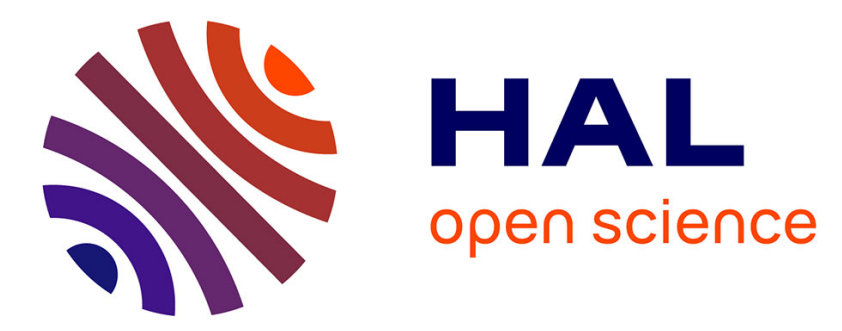

\title{
Gamma and electron NIEL dependence of irradiated GaAs
}

M. El Allam, C. Inguimbert, T. Nuns, A. Meulenberg, A. Jorio, I. Zorkani

\section{To cite this version:}

M. El Allam, C. Inguimbert, T. Nuns, A. Meulenberg, A. Jorio, et al.. Gamma and electron NIEL dependence of irradiated GaAs. NSREC 2016, Jul 2016, PORTLAND, United States. hal-01372019

\section{HAL Id: hal-01372019 \\ https://hal.science/hal-01372019}

Submitted on 26 Sep 2016

HAL is a multi-disciplinary open access archive for the deposit and dissemination of scientific research documents, whether they are published or not. The documents may come from teaching and research institutions in France or abroad, or from public or private research centers.
L'archive ouverte pluridisciplinaire HAL, est destinée au dépôt et à la diffusion de documents scientifiques de niveau recherche, publiés ou non, émanant des établissements d'enseignement et de recherche français ou étrangers, des laboratoires publics ou privés. 


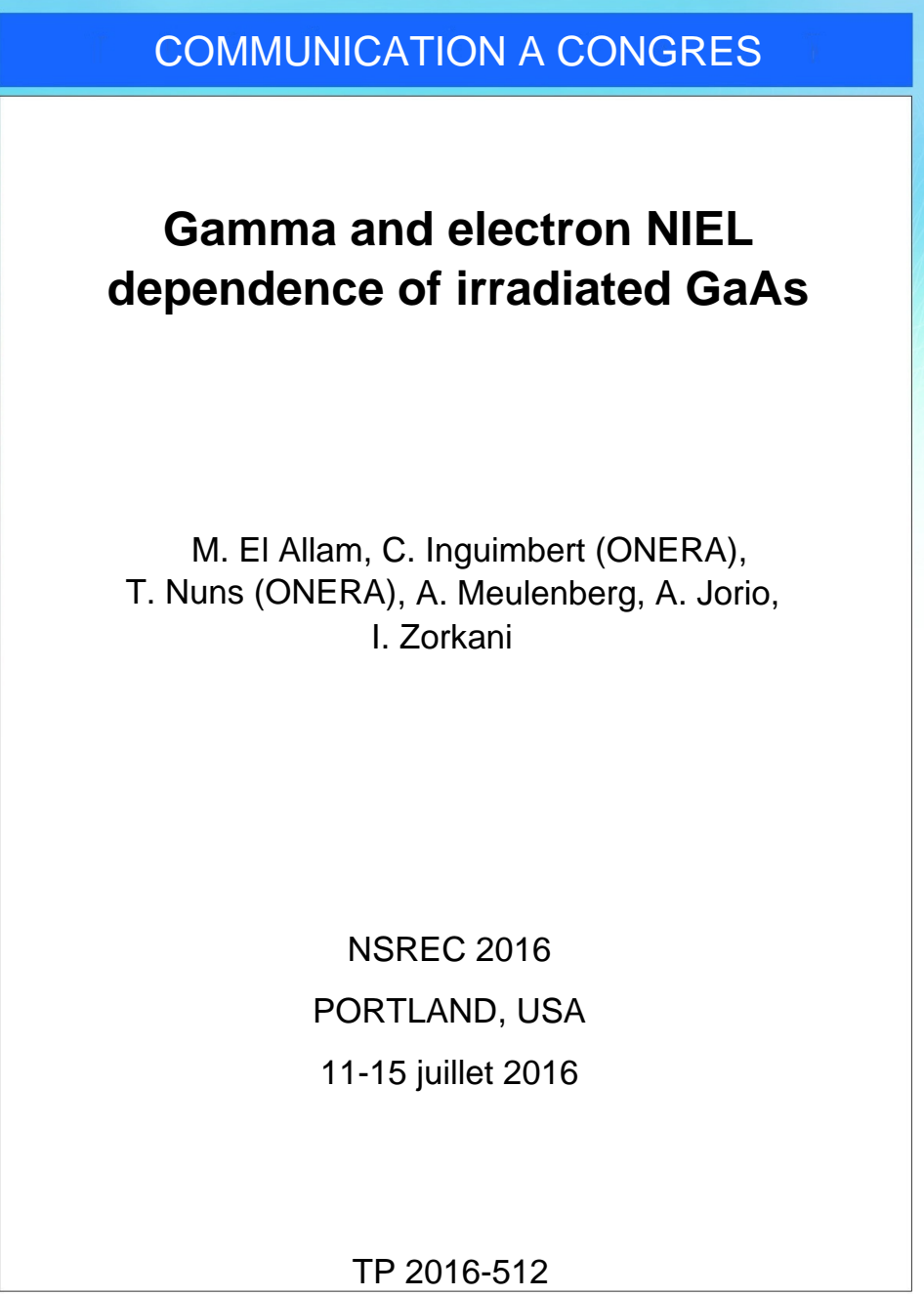

\section{0 and}

\section{ONERA}

THE FRENCH AEROSPACE LAB 



\title{
Gamma and electron NIEL dependence of irradiated GaAs
}

\author{
E. El Allam ${ }^{1}, \underline{\text { C. Inguimbert }}{ }^{2}$, T. Nuns ${ }^{2}$, A. Meulenberg ${ }^{3}$, A. Jorio ${ }^{1}$, I. Zorkani ${ }^{1}$
}

1) Laboratory of Solid State Physics, Faculty of Sciences Dhar el Mahraz, University Sidi Mohamed Ben Abdellah, P.B 1796 Atlas-Fez, Morocco.

2) ONERA-DESP, 2 avenue E. Belin, 31055 Toulouse, France

3) Science for Humanity Trust, Inc., USA

E. El Allam is with Faculty of Sciences Dhar el Mahraz, University Sidi Mohamed Ben Abdellah, P.B 1796 AtlasFez, Morocco. (tel: 21-2644256406, email: elmehdi.elallam@usmba.ac.ma).

Corresponding author: $\underline{C}$. Inguimbert is with ONERA-DESP, 2 avenue E. Belin, 31055 Toulouse, France

(tel: 33-562252734, email: Christophe.Inguimbert@onera.fr).

T. Nuns is with ONERA-DESP, 2 avenue E. Belin, 31055 Toulouse, France

(tel: 33-562252758, email: Thierry.Nuns@onera.fr).

A. Meulenberg is with Science for Humanity Trust, Inc., USA

(tel: 91-8042180541, email: mules333@ gmail.com).

A. Jorio is with Faculty of Sciences Dhar el Mahraz, University Sidi Mohamed Ben Abdellah, P.B 1796 AtlasFez, Morocco. (tel: 21-2661309965, email: a_jorio@ hotmail.com).

I. Zorkani is with Faculty of Sciences Dhar el Mahraz, University Sidi Mohamed Ben Abdellah, P.B 1796 AtlasFez, Morocco. (tel: 21-2661072710, email: izorkani@hotmail.com).

\begin{abstract}
Co}$ gamma rays are used to investigate the relevance of the NIEL scaling law for both electrons and gamma rays in Gallium Arsenide. A displacement threshold energy of $21 \mathrm{eV}$ is found for GaAs material.
\end{abstract}

Index terms- Space Environment, Displacement Damage, gamma rays, Non Ionizing Energy Loss.

Paper submitted at NSREC2016

Session: Basic Mechanisms of Radiation Effects in Electronic Materials and Devices: Displacement damage (Poster) 


\title{
Gamma and Electron NIEL Dependence of Irradiated GaAs
}

\author{
E. El Allam, C. Inguimbert, T. Nuns, A. Meulenberg, A. Jorio, and I. Zorkani
}

\begin{abstract}
In GaAs material, the radiation-induced degradations are demonstrated to vary according to the Non Ionizing Energy Loss (NIEL). But some discrepancies are still observed between experimental degradation measurements and predicted NIELs. The used displacement threshold energy $\left(T_{d}\right)$ varies, from one author to another, from $10 \mathrm{eV}$ up to $25 \mathrm{eV}$. A measurement made with ${ }^{60} \mathrm{Co}$ gamma rays is used to investigate the relevance of the NIEL scaling law for both electrons and gamma rays. $A T_{d}$ value of $21 \mathrm{eV}$ is found to be the most appropriate value, to properly scale the present experimental degradation measurements.
\end{abstract}

Index Terms - Space Environment, Displacement Damage, gamma rays, Non Ionizing Energy Loss.

\section{INTRODUCTION}

Charged particles populating the radiation belts can induce hazards in space missions. The radiations can produce atomic displacements in the lattice of semiconductor materials used in onboard electronics. The resulting defects lead to performance degradation that can go as far as failures [1]. Atomic displacements are produced mainly by the heavy ions and the protons of the space environment. Electrons, due to their lower mass, have a reduced efficiency to produce damage, several orders of magnitude lower than those of heavy particles [2]. However, because of their greater penetration capability, even they may produce some significant degradation in harsh environments rich in energetic electrons such as the Jovian environment. Laboratory sources of gamma rays, able to produce atomic displacements by means of secondary electron production [3], have been used historically to simulate the space radiation environment. For instance, the $\sim 1 \mathrm{MeV}^{60} \mathrm{Co}$ gamma rays produce a spectrum of Compton scattering secondary electrons in the $[\mathrm{keV}, \mathrm{MeV}]$ range.

The ability of an incident particle to produce operational damage in many devices may be given by the non-ionizing energy loss (NIEL). This term expresses the amount of energy deposited by an incident particle passing through a material and resulting in atomic displacements [2]. The theory of NIEL calculation is very well known [3-8], but the correlation with degradation measurements still suffers some discrepancies [1,

E. El Allam, A. Jorio, I. Zorkani are with: LPS-FSDM, University Sidi Mohamed Ben Abdellah, P.B 1796 Atlas-Fez, Morocco. (tel: 21-2644256406, e-mail: elmehdi.elallam@usmba.ac.ma).

C. Inguimbert, T. Nuns are with: ONERA, 2 av. E. Belin, 31055 Toulouse, France (tel: 33-562252734, e-mail: christophe.inguimbert@onera.fr).

A. Meulenberg is with: Science for Humanity Trust, Inc., USA. (tel: 918042180541, e-mail: mules333@gmail.com).
3, 9-15] that can be attributed to different reasons. In the NIEL calculation, a single parameter accounts for all physical processes involved in the defect production. The damage cascade mechanism and the subsequent annealing process, which lead to the production of stable defects, are assembled in the simple threshold displacement energy parameter $\left(\mathrm{T}_{\mathrm{d}}\right)$ that is poorly estimated for many materials.

In addition, dispersion in the experimental data can occur for a variety of reasons. For instance, the response of different electrical parameters is compared. These quantities can have different sensitivity to the damage production. Materials with different doping or impurity levels can respond differently to radiation induced degradations [14]. The inability to accurately differentiate the effects from Total Ionizing Dose (TID) and the Total Non Ionizing Dose effects (TNID) in experimental degradation measurements is another issue.

These uncertainties are especially important for light particles such as electrons and gamma rays for which the NIELs are strongly dependent on the displacement energy threshold $\mathrm{T}_{\mathrm{d}}$. For instance in Gallium Arsenide, the displacement threshold energy most commonly used is $10 \mathrm{eV}$ [3]. But recent measurements made on solar cells lead to a value closer to $21 \mathrm{eV}$ [13].

This work aims at discussing the radiation damage effects induced in GaAs after irradiation with electrons and gamma rays. To first order, it is shown that, within experimental uncertainties, the data are compatible with the NIEL scaling law. Nevertheless, the need for precision in the definition of the threshold displacement energy is highlighted for electrons and gamma rays.

\section{NIEL CALCULATION FOR GAMMA RAYS}

\section{A. Compton scattering}

Gamma photons can produce indirect atomic displacements by means of secondary electrons that are capable themselves to displace atoms by Coulombic interactions. Energetic photons $(>\mathrm{keV})$ can undergo three types of interactions with the electrons in a target: photoelectric absorption, Compton scattering and pair production. Between $100 \mathrm{keV}$ and up to some $\mathrm{MeV}$, Compton scattering is the dominant process. The Compton interactions lead to a broad secondary electron spectrum that spreads from some $\mathrm{keV}$ up to some $\mathrm{MeV}$. This secondary electron background produces in turn, point defects in the target materials. The amount of atomic displacements is a function of the secondary electron spectrum and of the capability of these electrons to produce Frenkel pairs $\left(\mathrm{NIEL}_{\mathrm{e}}\right)$. The NIEL of gamma rays $\left(\mathrm{NIEL}_{\gamma}\right)$ is given by: 


$$
N I E L_{\gamma}=\int_{0}^{E_{\max }} \frac{d S_{c}}{d Q}(Q) \cdot N I E L_{e}(Q) \cdot d Q
$$

Where $S_{c}$ is the secondary electron spectrum and $\operatorname{NIEL}_{e}(Q)$ is the NIEL of electrons at a given secondary energy $Q$. However, the Compton secondary electrons are slowed down by the target and intervening material. Most of secondary electrons have ranges of some hundred of nanometers and are stopped close to the region where they have been produced. In thick targets, a steady state is reached between the production of secondary electrons and their absorption by the active material. A simple estimate of the slowed down spectrum can be performed according to the method described by Summers et al. [3] and is presented in Fig. 1.

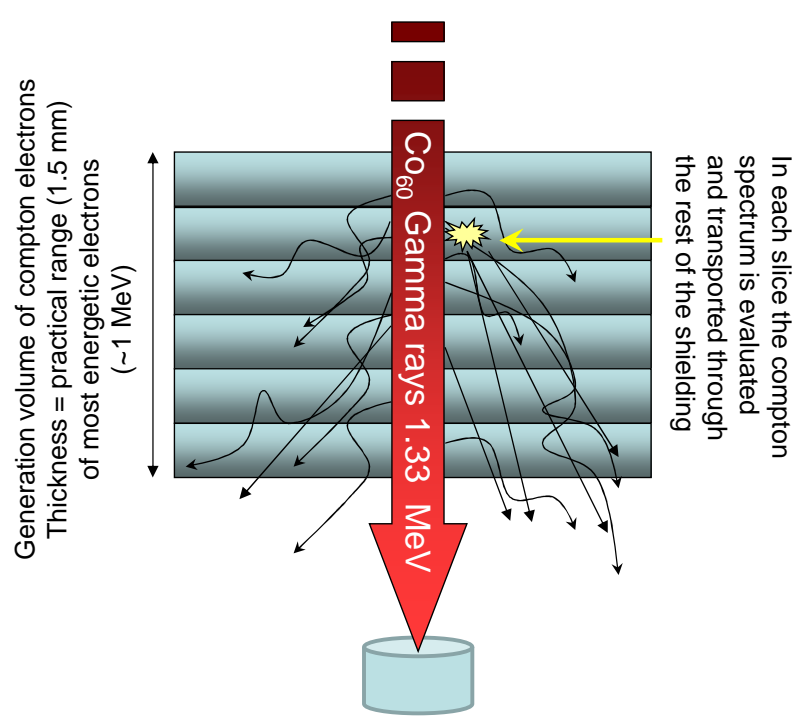

The active region is irradiated by compton electrons produced and slowed down in all the surounding volumes

Fig. 1. Secondary Compton electron spectrum calculated in a simple slab geometry.

Let us focus on the gamma rays produced by a ${ }^{60} \mathrm{Co}$ radiation source. This radioactive material produces at each disintegration two photons of respectively $1.33 \mathrm{MeV}$ and 1.17 $\mathrm{MeV}$. For the calculation, a production of gamma rays with an average energy of $1.25 \mathrm{MeV}$ has been considered. A $2 \mathrm{~mm}$ equivalent shielding of aluminum is assumed for the calculation. It corresponds to the practical range of secondary electrons $(\sim 2 \mathrm{~mm})$, i.e. all the electrons produced at a distance larger than the practical range of the most energetic electron of the Compton spectrum are absorbed by the shielding and will not contribute to the slowed down spectrum. The parallelepipedic shielding is sliced in elementary layers in which the Compton spectrum is evaluated. Then, as described in Fig 1, the spectrum of each slice is transported through the rest of the shielding down to the studied target. The slowed down spectrum that reaches the device is just the sum of all the transported spectra.

The Compton electron spectra are estimated according to the Klein Nishina cross-section formula $\mathrm{d} \sigma_{\mathrm{c}} / \mathrm{d} \Omega$ [16] that gives the differential cross section of photons scattered from a single free electron.

$$
\begin{aligned}
\frac{d \sigma_{c}}{d \Omega} & =\frac{r_{e}^{2}}{2}\left(\frac{1}{1+\frac{E_{\gamma}}{m_{e} c^{2}}(1-\cos (\theta))}\right)^{2} \\
& \times\left(\frac{1}{1+\frac{E_{\gamma}}{m_{e} c^{2}}(1-\cos (\theta))}+1+\frac{E_{\gamma}}{m_{e} c^{2}}(1-\cos (\theta))-1+\cos ^{2}(\theta)\right)
\end{aligned}
$$

With:

$$
E_{\gamma}^{\prime}=E_{\gamma}\left(\frac{1}{1+E_{\gamma}(1-\cos (\theta))}\right)
$$

and $\mathrm{r}_{\mathrm{e}}^{2} \sim 7.940610^{-30} \mathrm{~m}^{2}$ and $\mathrm{m}_{\mathrm{e}} \mathrm{c}^{2}=0.511 \mathrm{MeV}$. $\mathrm{E}_{\gamma}$ is the energy of the incident photon and $\mathrm{E}_{\gamma}{ }_{\gamma}$ is the energy transferred to the secondary electron. The spectrum of Compton electron shown in Fig. 2 is then given by:

$$
\frac{d \sigma_{c}}{d \Omega} \cdot \frac{d \Omega}{d E_{\gamma}^{\prime}}
$$

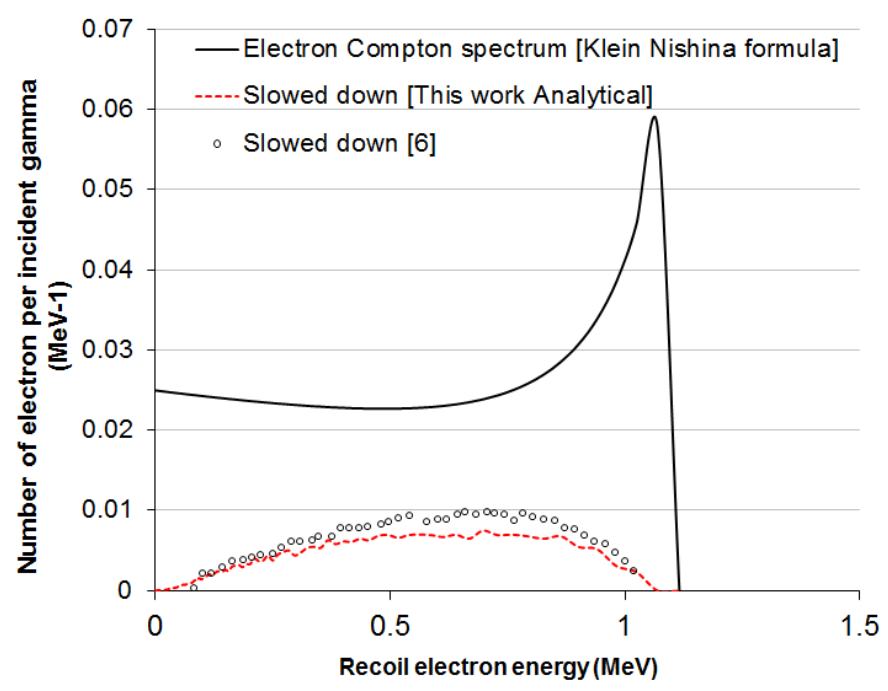

Fig. 2. Comparison of the secondary Compton electron spectrum calculated according to the formula (2) and the slowed down spectrum calculated analytically. The agreement with the Monte Carlo simulation of Akkerman [6] et al. is quite satisfactory.

The secondary electron spectrum has been transported through thin foils of aluminum according to the transmission probability given by Rao [17] and assuming a normal incidence. If the transmission probability of an electron of energy $\mathrm{E}_{\gamma}{ }_{\gamma}$ through a shielding of thickness $t$ is called $\eta\left(\mathrm{E}_{\gamma}{ }_{\gamma}, t\right)$. The transmitted spectrum can be expressed by the following equation:

$$
\frac{d \sigma}{d Q_{\gamma}}=\frac{d \sigma_{c}}{d \Omega} \cdot \frac{d \Omega}{d E_{\gamma}^{\prime}} \cdot \eta\left(E_{\gamma}^{\prime}, t\right) \cdot \frac{d E_{\gamma}^{\prime}}{d Q}
$$

Where $\mathrm{Q}$ is the energy of the transmitted electrons. $\mathrm{dE}_{\gamma}{ }_{\gamma} / \mathrm{dQ}$ can be deduced from the range/energy relationship [18]. This analytical calculation leads to the slowed down spectrum 
presented in Fig. 2 (dotted line) in relatively good agreement (30\% difference) with the Monte Carlo simulation of Akkerman et al [6] (white square).

\section{B. GEANT4 calculation}

Some more accurate calculations have been performed with the GEANT4 [19-21] Monte Carlo toolkit. The GEANT4 library (9.6 patch 02 version) [19-21] is a C++ toolkit assembled by an international collaboration, that describes the interaction of radiations with matter. The slowed down spectrum produced by a unidirectional beam of $1.25 \mathrm{MeV}$ gamma rays crossing an aluminum shield has been performed with GEANT4 and compared to the analytical model.

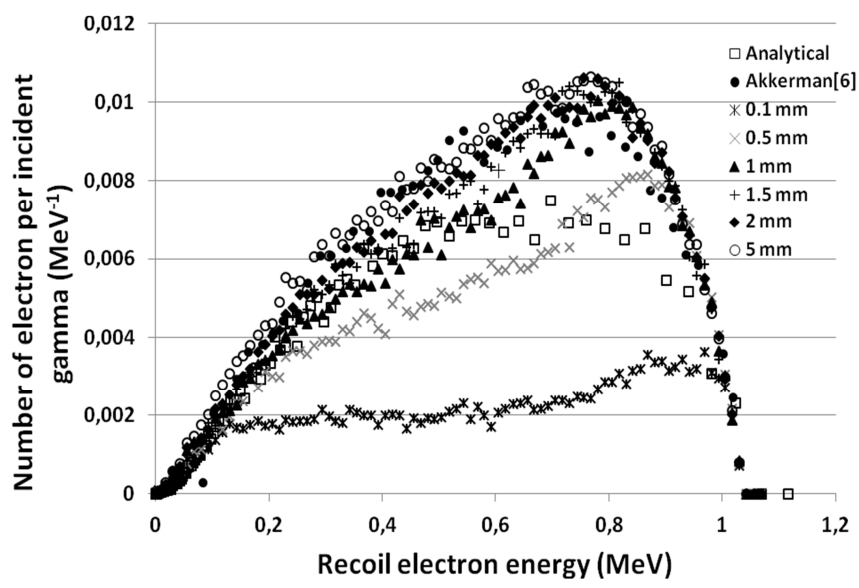

Fig. 3. Slowed down spectra calculated by GEANT 4 for secondary electrons generated by $60 \mathrm{Co}$ gamma rays in the aluminum shielding with a thickness of $0.1,0.5,1,1.5,2$, and $5 \mathrm{~mm}$. Results are in very good agreement with the result of Akkerman [6]. The analytical calculation provides relatively satisfactory results.

Anagolously to the analytical approach, the Monte Carlo calculation simulates the irradiation of an aluminium target of a given thickness with a unidirectional beam of monoenergetic gamma rays $(1.25 \mathrm{MeV})$. The energetic spectra of the secondary electrons produced in the shielding and the slowed down spectrum that irradiates the target are sampled. Aluminum shielding thicknesses have been varied from 0.1 $\mathrm{mm}$ up to $5 \mathrm{~mm}$ (Fig.3). The standard electromagnetic physics model of GEANT4 [21] has been chosen for the simulations. $10^{7}$ photons have been simulated at each run.

The slowed down spectra presented in Fig. 3 have been normalized per incident photon. As can be seen in Fig.3, the agreement between the different methods is quite good, in view of the simplifying assumptions of the analytical approach. The agreement with the Monte Carlo simulation of Akkerman et al. [6] is also very good for the $2 \mathrm{~mm}$ shielding thickness.

Afterwards, this calculated slowed down spectrum of secondary electrons has been used to obtain the NIEL for ${ }^{60} \mathrm{Co}$ gamma rays.

\section{NIEL for ${ }^{60}$ Co}

According to the formula (1), the secondary electron spectra calculated previously have been used to quantify in Gallium Arsenide the $\mathrm{NIEL}_{\gamma}$ of the ${ }^{60} \mathrm{Co}$ gamma rays.
Different electron NIEL curves have been used for the calculation. NIELs from different models have been tested [2, 3, 8]: NEMO [2] developed by ONERA and available since 2006 through the OMERE free package [22], the SR-NIEL [23] developed by the INFN in 2014 that proposes, through a dedicated web site, a Screened Relativistic (SR) treatment for calculating the displacement damage and nuclear stopping powers, and the reference work of Summers [3] published in 1993. Some other authors [5-7] propose their own NIEL calculations based on similar models. The provided NIELs are very close to each others, they are not presented here. As can be seen in the Fig. 4, NEMO [2] and SR-NIEL [21] simulation toolkits provide NIEL close to each others. The NIEL of ref. [3] is slightly larger. But the difference remains lower than $20 \%$ at worst.

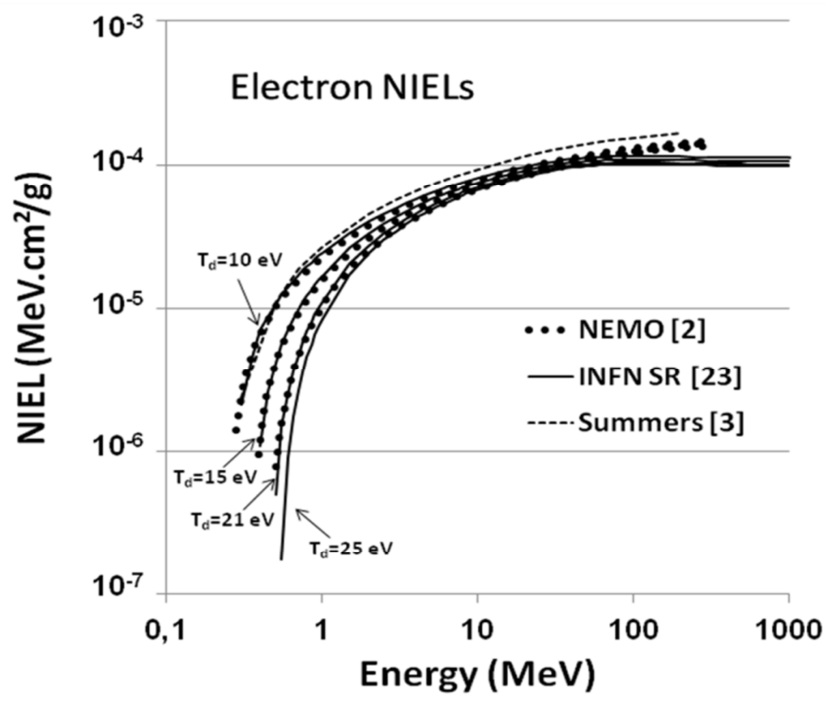

Fig. 4. Different GaAs electron NIEL curves used to calculate the ${ }^{60} \mathrm{Co}$ NIEL.

The impact of the threshold displacement energy on the NIEL curves has also been studied. $T_{d}$ has been varied in the range [10 eV, $25 \mathrm{eV}]$ (Fig. 4). Beyond $10 \mathrm{MeV}$, the use of different $T_{d}$ values leads only to slight differences on the NIEL (Fig. 4). On the other hand, below $1 \mathrm{MeV}$, the NIEL depends closely on the displacement threshold energy. The NIEL of electrons is an increasing function whose upper part is not much affected by the value of $T_{d}$. In counterpart, the threshold of the NIEL curve is strongly dependent on the $T_{d}$ value. From Fig. 4, the electron energy required to create the displacement damage is approximately $0.3 \mathrm{MeV}$, corresponding to a threshold displacement energy $\mathrm{T}_{\mathrm{d}}$ of $\sim 10 \mathrm{eV}$, this energy is changed to $0.55 \mathrm{MeV}$ when $\mathrm{T}_{\mathrm{d}}$ is changed to $25 \mathrm{eV}$.

In this work, a parametric study has been carried out to investigate the importance of the threshold displacement energy on the value of the ${ }^{60}$ Co NIEL $\gamma$ in Gallium Arsenide. The ${ }^{60} \mathrm{Co}$ NIEL $\gamma$ were evaluated with the slowed down spectrum calculated with GEANT4 using $5 \mathrm{~mm}$ thick aluminum shielding and the different $\mathrm{NIEL}_{\mathrm{e}}$ curves calculated previously. ${ }^{60} \mathrm{Co}$ NIEL $\gamma$ has been calculated in Gallium Arsenide for four $\mathrm{T}_{\mathrm{d}}$ values $(10 \mathrm{eV}, 15 \mathrm{eV}, 21 \mathrm{eV}$, and $25 \mathrm{eV})$ (Table 1). NIEL values provided by different authors [3, 6, 24] have been added in the table for comparison. The NIEL in 
GaAs is commonly estimated using a threshold displacement energy of $10 \mathrm{eV}$ for both $\mathrm{Ga}$ and As nuclei. Using these values our calculation is in good agreement with the NIEL given by Akkerman [6]. NEMO [2] and INFN-SR NIEL calculator give respectively $8.5310^{-8} \mathrm{MeV} . \mathrm{cm}^{2} / \mathrm{g}$ and $9.110^{-8} \mathrm{MeV} . \mathrm{cm}^{2} / \mathrm{g}$ ( $6 \%$ difference). These two values are close to the value given by Akkerman [6]: $9.7 \quad 10^{-8} \quad \mathrm{MeV} . \mathrm{cm}^{2} / \mathrm{g} \quad(\sim 13 \%$ difference). The value given by Shatalov [24] is slightly higher: $1.4210^{-07} \mathrm{MeV} . \mathrm{cm}^{2} / \mathrm{g}$ (+ 60\%). All these calculations provide a NIEL $\gamma$ of ${ }^{60} \mathrm{Co}$ gamma rays in Gallium Arsenide around fifty times lower than the value of reference [3].

TABLE I

The NIEL of ${ }^{60}$ Co Gamma Rays In Gallium ARSENide CALCUlated BY DIFFERENT SOURCES WITH DIFFERENT THRESHOLD DISPLACEMENT ENERGY $T_{D}$.

\begin{tabular}{|l|c|c|c|}
\hline & $\begin{array}{c}\mathrm{T}_{\mathrm{d}}(\mathrm{As}) \\
(\mathrm{eV})\end{array}$ & $\begin{array}{c}\mathrm{T}_{\mathrm{d}}(\mathrm{Ga}) \\
(\mathrm{eV})\end{array}$ & $\begin{array}{c}{ }^{60} \mathrm{Co} \mathrm{NIEL} \gamma \\
\left(\mathrm{MeV} \cdot \mathrm{cm}^{2} / \mathrm{g}\right)\end{array}$ \\
\hline NEMO [2] & 10 & 10 & $8,53 \mathrm{E}-08$ \\
\hline NEMO [2] & 15 & 15 & $4,76 \mathrm{E}-08$ \\
\hline NEMO [2] & 21 & 21 & $2,45 \mathrm{E}-08$ \\
\hline INFN SR [23] & 10 & 10 & $9,10 \mathrm{E}-08$ \\
\hline INFN SR [23] & 15 & 15 & $5,03 \mathrm{E}-08$ \\
\hline INFN SR [23] & 21 & 21 & $2.55 \mathrm{E}-08$ \\
\hline INFN SR [23] & 25 & 25 & $1,61 \mathrm{E}-08$ \\
\hline Summers [3] & 10 & 10 & $9,25 E-06$ \\
\hline Akkerman [6] & 10 & 10 & $9,70 E-08$ \\
\hline Shatalov [24] & 10 & 10 & $1.42 E-07$ \\
\hline
\end{tabular}

As can be seen in the table, the ${ }^{60}$ Co gamma rays NIEL decreases with increasing $T_{d}$ values. It goes from $\sim 910^{-8}$ $\mathrm{MeV} . \mathrm{cm}^{2} / \mathrm{g}$ down to $\sim 1,610^{-8} \mathrm{MeV} . \mathrm{cm}^{2} / \mathrm{g}$ when $\mathrm{T}_{\mathrm{d}}$ goes from $10 \mathrm{eV}$ up to $25 \mathrm{eV}$. The NIEL of gamma rays is strongly dependent on the $T_{d}$ value. Therefore, the selection of the threshold displacement energy plays a crucial role in the NIEL calculation for both electrons (below $\sim 1 \mathrm{MeV}$ ) and gamma rays.

\section{EXPERIMENTAL DATA}

In the case of Gallium Arsenide, Jorio and Khanna [14, 15] reported a full set of data where the defect introduction rate plotted as a function of the incident energy is compared to corresponding NIELs (Fig.5). These experimental data include measurements made with heavy ions, protons, neutrons electrons and gamma rays. The measurements are in relatively good agreement with NIEL calculations. As can be seen in Fig. 5, the NIEL of ref. [3] overestimates the real degradation by a factor 100 . On the other hand the experimental measurements [15] are in quite good agreement with our NIEL values. The gamma NIEL has been estimated for 4 different threshold displacement energies $(10,15,21$, and $25 \mathrm{eV})$. Our NIEL result for $\mathrm{T}_{\mathrm{d}}=10 \mathrm{eV}$, in agreement with that of Akkerman [6] for GaAS, is still larger by a factor 4 than the observed degradation ("exp Data, Co60 [15]" in Fig. 5). Using a threshold displacement energy of $21 \mathrm{eV}$ instead of the classically used $10 \mathrm{eV}$, leads to a far better agreement (Fig. 5).

\section{DISCUSSION}

One important challenge for estimating the damage level introduced by radiation in materials is the definition of the threshold displacement energy $\mathrm{T}_{\mathrm{d}}$. As shown in the previous sections this is particularly important for gamma rays (Fig. 5), and low energy electrons (Fig. 4), which NIELs are very sensitive to $T_{d}$. This issue is still incompletely solved, because $\mathrm{T}_{\mathrm{d}}$ is very difficult to define accurately, and this may result in significant errors in the NIEL evaluation.

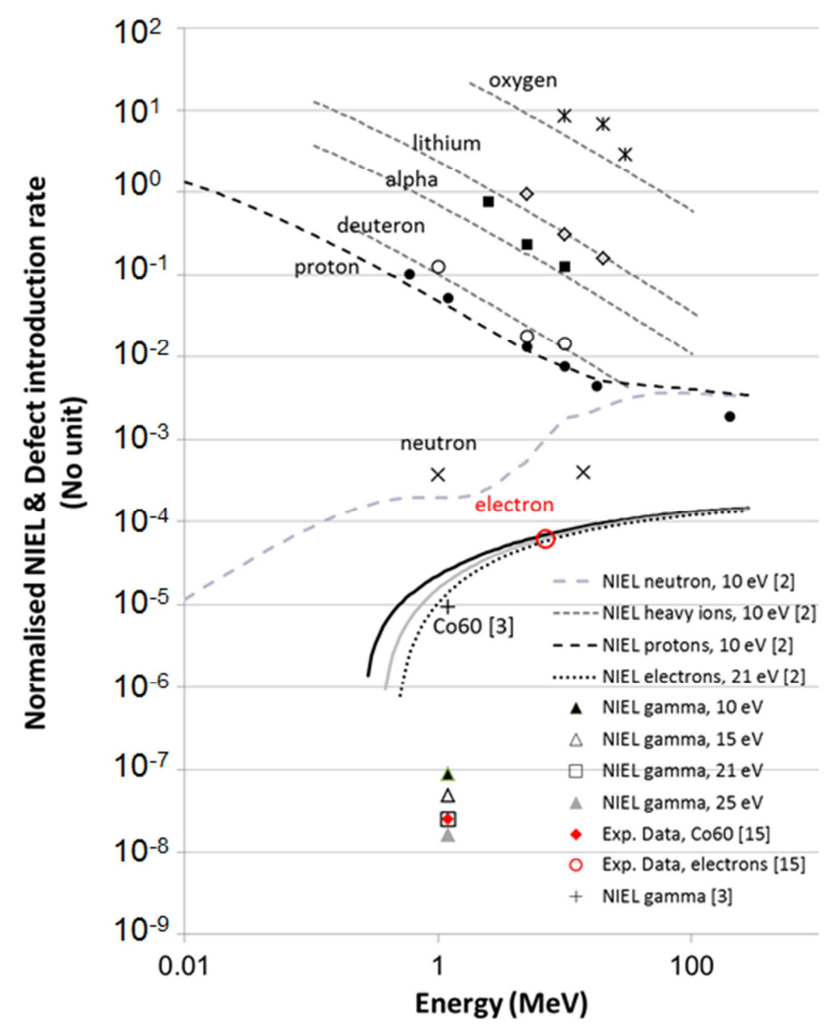

Fig. 5. Correlation of the degradation measurements with the NIEL. Our NIEL calculation (for the $1.25 \mathrm{MeV}$ gammas of ${ }^{60} \mathrm{Co}$, using $\mathrm{T}_{\mathrm{d}}=10 \mathrm{eV}$ ) provides results in better agreement than the NIEL of ref. [3]; but, it still overestimates the degradation by a factor 4 .

Many studies deal with the radiation induced damage production in GaAs [25-40]. Many authors tried to define experimentally the threshold displacement energy. From one author to another, $\mathrm{T}_{\mathrm{d}}$ can vary from $10 \mathrm{eV}$ up to $25 \mathrm{eV}$ [2534]. This leads to a large uncertainty in the definition of the NIEL for ${ }^{60}$ Co gamma rays.

Usually the value of $T_{d}$ is deduced experimentally, by measuring the introduction rates of the various defects created by electron irradiation (direct measurement) or by measuring the change in device characteristics such as the change in minority carrier lifetime, carrier removal and mobility (indirect measurements). The degradation of these electrical properties is supposed to be proportional to the amount of defects present in the bandgap and consequently to the quantity of atoms displaced by the incident particles.

There are quite a number of experimental studies of the threshold displacement energy in GaAs. Despite these studies, there are still uncertainties about the useful value of $T_{d}$. The experimental data of Barry [25] indicate that the electron 
energy required to create the damage in GaAs devices is approximately $270 \mathrm{keV}$, corresponding to a threshold displacement energy $T_{d}$ of $\sim 10 \mathrm{eV}$. Comparable values of $T_{d}$ $(9-10 \mathrm{eV})$ has been obtained in ref. [26] by using Deep Level Transient Spectroscopy (DLTS). Another work, which used the same technique, indicates a threshold displacement energy of $15.5 \mathrm{eV}$ [27]. This result is in disagreement with the experimental data obtained by Meulenberg [28], which concluded that the electrons with energies lower than $600 \mathrm{keV}$ did not produce any damage in GaAs devices. That corresponds to a displacement damage threshold of around 25 $\mathrm{eV}$ [28]. A comparable value was obtained in ref. [29]. This is slightly greater than the value of the threshold displacement energy measured by Grimshaw [30] and Pegler [31], which is 17-18 eV. The conductivity measurements of Thommen [32] seem to be best correlated with the NIEL using a threshold displacement energy of $15 \mathrm{eV}$ (Fig. 6). Recent solar cells degradation measurements of Baur et al [13] indicate a value of $21 \mathrm{eV}$. And the gamma induced degradation measurements $[14,15]$ presented in this work seem to be explained using a threshold displacement energy of $21 \mathrm{eV}$, comparable to the 25 $\mathrm{eV}$ given in ref. [33].

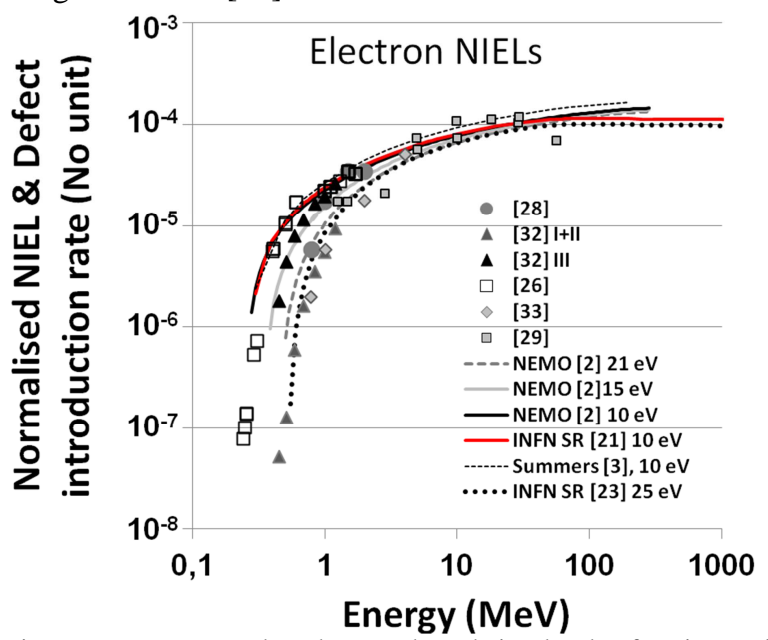

Fig. 6. NIEL compared to damage degradation levels of various references. The NIEL has been calculated for different threshold energies.

In Fig. 6, the NIEL of electrons in GaAs are presented for different threshold energies [ $10 \mathrm{eV}, 25 \mathrm{eV}]$, and compared to some of the cited bibliographic data [26, 28, 29, 32, 33]. As can be seen in fig. 6 , the damage function is quite well reproduced. But, there is a large uncertainty on the definition of the threshold, that can go from $\sim 300 \mathrm{keV}\left(\mathrm{T}_{\mathrm{d}} \approx 10 \mathrm{eV}\right)$ up to $600 \mathrm{keV}\left(\mathrm{T}_{\mathrm{d}} \approx 25 \mathrm{eV}\right.$ ) (Fig. 6). These discrepancies among the data can have many different causes. The low-energy electrons generated by the ${ }^{60} \mathrm{Co}$ gamma are demonstrated to introduce in GaAs five different types of electron traps (i.e., defect levels E1 to E5) $[36,26]$.The annealing behavior of these defects has been studied by Thommen [32]. Three annealing stages can be observed when GaAs is irradiated by $1 \mathrm{MeV}$ electrons at $77 \mathrm{~K}$. Stage I occurs at $235 \mathrm{~K}$, stage II at $280 \mathrm{~K}$ and stage III at 520 K. Another study carried out by Pons et al. [37], have shown that all the defects introduced at room temperature in GaAs by $1 \mathrm{MeV}$ electrons are removed in stage III, then new defects appear at this stage. It was also noted that the value of threshold displacement energy for defects annealing in stages I and II is larger than the value for defects that anneal in stage III (Fig. 6). A study carried out by Rezazahed [38] demonstrated that the stages I and II are ascribed to divacancy $\left(\mathrm{V}_{\mathrm{As}}-\mathrm{V}_{\mathrm{Ga}}\right)$, or the divacancy complexed with an interstitial $\left(\mathrm{As}_{\mathrm{I}}\right.$ or $\mathrm{Ga}_{\mathrm{I}}$ ), and the annealing in these two first stages involves dissociation, or internal recombination of these defects [38]. Wurschum et al. [39] observed that the stages I and II defects cannot be generated unless the displacement threshold energy is greater than $20 \mathrm{eV}$. The annealing stage III is attributed to the partial recombination of vacancy-interstitial pair such as $\left(\mathrm{V}_{\mathrm{As}}-\mathrm{As}_{\mathrm{I}}\right)$ through the migration of interstitial $\left(\mathrm{As}_{\mathrm{I}}\right)$ [40]. From all these studies, it is clear that the displacement threshold energy is different for different types of defects generated by low-energy radiation. At room temperature the direct DLTS method seems to be the most reliable way for determining the displacement threshold energy [26]. At this temperature, the electron-induced defects in GaAs are stable, and ref. [26] seems to show that the 5 different majority-carrier traps all have quite the same $T_{d}$ value close to $10 \mathrm{eV}$.

The observed scatter within the threshold displacement energy can also be attributed to the various indirect method employed to deduce its value. These indirect measurements are less accurate and present an important variability related to their different sensitivities. Different electrical parameters are measured; conductivity for Thommen [32], carrier removal rate in ref. [28, 29], mobility in ref. [28], carrier lifetime in ref. [25], and diffusion length in ref. [33]. Warner et al. [34] underline the fact that different electrical parameters associated with the same GaAs device seem to follow different energy dependences with NIEL. The photocurrent and photovoltage of GaAs solar cells seems to follow more likely a quadratic dependence with NIEL. This suggests that different electrical parameters of the GaAs-devices can have different sensitivity to the defects production. In addition, the tested materials are not exactly the same from one reference to another. Both, the degree of purity and the doping levels can differ. Khanna [15] showed that the defect introduction rate depends strongly on the doping level. It can be multiplied by 10 when the doping level of silicon is reduced from $10^{16} \mathrm{~cm}^{-3}$ to $10^{15} \mathrm{~cm}^{-3}$. The effect of annealing must also be taken into account. It can lead to an apparent change in the displacement threshold energy, by modifying the nature of the produced defects and changing the final damage level. Barry et al.[35] have shown that $95 \%$ of the damage introduced in GaAs LEDs irradiated with ${ }^{60} \mathrm{Co}$ gamma can be annealed either by heating to $200{ }^{\circ} \mathrm{C}$ for 24 hours, or by forward biasing at $100 \mathrm{~mA}$. This is contrary to what was observed in the case of higher energy electrons and protons, where just $40 \%$ of the damage can be annealed. Therefore, the damage produced by ${ }^{60} \mathrm{Co}$ gamma radiation seems to be more sensitive to the annealing processes. In that scope, the total ionizing dose and its deposition rate could be an important parameter that can impact the final damage level. All these factors make it difficult to give a single value of the threshold displacement energy.

It is also noteworthy that these discrepancies can be associated with uncertainties in the experimental results. The test conditions can play an important role for gamma irradiations. For gamma rays the "dose strengthening" mechanism is taken into account by putting a few $\mathrm{mm}$ of 
aluminum shielding in front of the sample to homogenize the ionizing dose. The presence or not of this shielding will change strongly the spectrum of the secondary electrons (Fig.3). As can be seen in Fig.3, the secondary electron spectrum changes rapidly while the steady state is not achieved. In Table 2 the NIEL of ${ }^{60} \mathrm{Co}$ gamma in GaAs has been calculated as a function of the aluminum shielding thickness. $T_{d}=10 \mathrm{eV}$ has been chosen for the calculation, and the aluminum thickness has been varied from $0.1 \mathrm{~mm}$ up to 5 $\mathrm{mm}$. The difference (NIEL/damage coefficient) with the measurements of ref. $[14,15]$ is reported in the table. It is clear that the NIEL of gamma rays is very sensitive to the thickness of the shielding material that surrounds the active region of the device. In our case, the gamma NIEL calculated with the shielding thickness of $0.1 \mathrm{~mm}$ is the closest to the experimental values.

\section{TABLE II}

THE NIEL OF ${ }^{60}$ Co GAMMA RAYS IN GALLIUM ARSENIDE AS A FUNCTION OF THE ALUMINUM SHIELDING THICKNESS. COMPARISON WITH THE DEFECT INTRODUCTION RATE FOR GAMMA [14, 15].

\begin{tabular}{|c|c|c|c|c|}
\hline $\begin{array}{c}\mathrm{Al} \\
\text { thickness } \\
(\mathrm{mm})\end{array}$ & $\begin{array}{c}\mathrm{T}_{\mathrm{d}}(\mathrm{As}) \\
(\mathrm{eV})\end{array}$ & $\begin{array}{c}\mathrm{T}_{\mathrm{d}}(\mathrm{Ga}) \\
(\mathrm{eV})\end{array}$ & $\begin{array}{c}{ }^{60} \mathrm{Co} \mathrm{NIEL} \gamma \\
\left(\mathrm{MeV} . \mathrm{cm}^{2} / \mathrm{g}\right)\end{array}$ & $\begin{array}{c}\text { NIEL/damage } \\
\text { coefficient } \\
{[14,15]}\end{array}$ \\
\hline 5 & 10 & 10 & $8,82 \mathrm{E}-08$ & 3,51 \\
\hline 2 & 10 & 10 & $8,52 \mathrm{E}-08$ & 3,4 \\
\hline 1,5 & 10 & 10 & $8.28 \mathrm{E}-08$ & 3,3 \\
\hline 1 & 10 & 10 & $7,88 \mathrm{E}-08$ & 3,14 \\
\hline 0,5 & 10 & 10 & $6,48 \mathrm{E}-08$ & 2.58 \\
\hline 0,1 & 10 & 10 & $2,77 \mathrm{E}-08$ & 1.1 \\
\hline
\end{tabular}

The nature of the shielding materials can also be a source of discrepancies. The Fig. 7 shows the calculated slowed down spectra of secondary electrons produced by $1.25 \mathrm{MeV}$ gamma rays in various materials. As can be seen from this figure, the slowed down spectrum of secondary electrons will strongly depend on the nature of the materials in which they are produced. The presence of metallizations on the device can also affects the damage level.

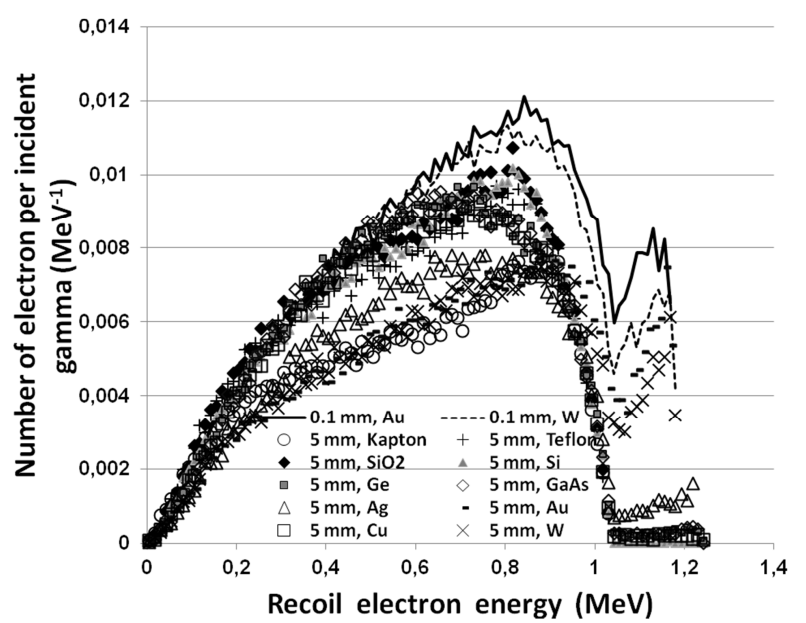

Fig. 7. Slowed down spectra calculated by GEANT 4 for secondary electrons generated by ${ }^{60} \mathrm{Co}$ gamma rays in various materials.
From another point of view, The NIEL mechanism and calculations are a unifying and simplifying principle for predicting radiation damage to many solid-state devices. However, it has limitations in the low-energy radiation regime where point defects may dominate the electrical degradation. The work reported by Inguimbert et al. [11] indicates that there is strong uncertainty in calculation of electron NIEL at energies near threshold, and certainly that may include also gamma. The large variation in threshold values measured or determined over the years for GaAs devices $\left(10<\mathrm{T}_{\mathrm{d}}<25 \mathrm{eV}\right)$ represents an artifact of the attempt to fit data. All authors have different values, but are used in the same fashion. Since all could be labeled as $T_{d}$, this could be confusing. Device degradation depends on multiple factors, it may not be uniquely dependent on the displacement threshold energy. It may depend on the threshold for a particular type of defect. Nevertheless, the damage levels of the devices have also an apparent threshold. Therefore, a more useful parameter could be the damage or degradation threshold at room temperature. To overcome the issue of discrepancy between experimental degradation measurements and predicted NIELs, the distinction between displacement and damage thresholds could be made. In other words, if a threshold model is used to fit the device damage data ( $\neq$ defect), a damage threshold, rather than a displacement threshold can be defined. A similar process is already in use for solar cells degradation estimations that show a comparable spread within the data. For GaAs, the set of experimental data reported in Fig. 6 leads to a value around $\sim 15 \mathrm{eV}$ which is the most representative of the data found in the literature.

\section{CONCLUSION}

The NIEL scaling law which is validated in GaAs for heavy particles (heavy ions, protons) seems to be more questionable for light particles such as electrons and gamma rays. The observed discrepancies can be due to uncertainties in the experimental data. For gamma rays, the test conditions are a potential source of error. From the simulation stand point, a relatively large uncertainty on the value of the threshold displacement energy is observed. From one author to another $\mathrm{T}_{\mathrm{d}}$ can vary from $10 \mathrm{eV}$ up to $25 \mathrm{eV}$. This leads to a large uncertainty on the definition of the NIEL of ${ }^{60} \mathrm{Co}$ gamma rays. The defect introduction rate of ref. $[14,15]$ is found to be in agreement with the NIEL prediction for a threshold displacement energy of $21 \mathrm{eV}$. This result is in agreement with other degradation measurements performed with gamma rays and with recent measurements made with GaAs solar cells.

A lot of factors can affect the definition of $T_{d}$. In particular, the type of measurements. If looking at actual defects, the low value of $\sim 10 \mathrm{eV}$ seems to be the most reliable value. If looking at defects that degrade performance of the devices a higher value seems to be more relevant (up to $25 \mathrm{eV}$ is possible). An effective displacement threshold energy $>20 \mathrm{eV}$ seems to be more appropriate for gamma rays in GaAs. An average value of $\sim 15 \mathrm{eV}$ seems to be the most representative of the data found in the literature. It can be defined as the damage energy threshold ( $\neq$ displacement energy threshold). 


\section{REFERENCES}

[1] J. R. Srour, "Review of displacement damage effects in silicon devices," IEEE Trans. Nucl. Sci., vol. 50, no. 3, pp. 653-670, Jun. 2003.

[2] C. Inguimbert, and R. Gigante, "NEMO: A code to compute NIEL of protons, neutrons, electrons, and heavy ions," IEEE Trans. Nucl. Sci., vol. 53, no. 4, pp. 1967-1972, Aug. 2006.

[3] G. P. Summers, E. A. Burke, P. Shapiro, S. Messenger, and R.J. Walters, "Damage correlations in semiconductors exposed to gamma, electron and proton radiations," IEEE Trans. Nucl. Sci., vol. 40, no. 6, pp. 1372 1379, Dec. 1993.

[4] S. R. Messenger, E. A. Burke, G. P. Summers, M. A. Xapsos, R. J. Walters, E. M. Jackson, and B. D. Weaver, "Non ionizing energy loss (NIEL) for heavy ions," IEEE Trans. Nucl. Sci., vol. 46, no. 6, pp. 1595 1602, Dec. 1999.

[5] S. R. Messenger, R. J. Walters, E. Burke, G. P. Summers, and M. A. Xapsos, "NIEL and damage correlations for high-energy protons in gallium arsenide devices," IEEE Trans. Nucl. Sci., vol. 48, no. 6, pp. 2121-2126, Dec. 2001.

[6] A. Akkerman, J. Barak, M. B. Chadwick, J. Levinson, M. Murat, and Y. Lifshitz, "Updated NIEL calculations for estimating the damage induced by particles and gamma-rays in $\mathrm{Si}$ and GaAs," Rad. Phys. and Chem. Vol. 62, pp. 301-310, 2001.

[7] I. Jun, W. Kim, and R. Evans, "Electron nonionizing energy loss for device applications," IEEE Trans. Nucl. Sci., vol. 56, no. 6, pp. 3229 3235, Dec. 2009.

[8] M. J. Boschini, C. Consolandi, M. Gervasi, S. Giani, D. Grandi, V. Ivanchenko, P. Nieminem, S. PenBOtti, P. G. Rancoita, M. Tacconi, E. ESA, and A. G. Noordwijk," Nuclear and non-ionizing energy-loss for Coulomb scattered particle from low energy up to relativistic regime in space radiation environment ", Proceedings of the 12th ICATPP Conference on Astroparticle, Particle, Space Physics and Detectors for Physics Applications, Villa Olmo (Como, Italy), 7-8 October, 2010.

[9] G. P. Summers, E. A. Burke, and M. A. Xapsos, "displacement damage analogs to ionizing radiation effects," Rad. Meas., Vol. 24, no. 1, pp. 1 $8,1995$.

[10] S. R. Messenger G. P. Summers, E. A. Burke, R. J. Walters, and M. A. Xapsos, "Modeling solar cell degradation in space: A comparison of the NRL displacement damage dose and JPL equivalent fluence approaches," Prog. Phot: Res. Appl., vol. 9, pp. 103-121, 2001.

[11] C. Inguimbert, P. Arnolda, T. Nuns, and G. Rolland, "Effective NIEL in silicon: Calculation using molecular dynamic results," IEEE Trans. Nucl. Sci., vol. 57, no. 4, pp. 1915-1923, Dec. 2010.

[12] C. Inguimbert, and S. Messenger, "Equivalent displacement damage dose for on-orbit space application," IEEE Trans. Nucl. Sci., vol. 59, no. 6, pp. 3117-3125, Dec. 2012.

[13] C. Baur, M. Gervasi, P. Nieminen, S. Pensotti, P.G. Rancoita, and M. Tacconi, "NIEL dose dependence for solar cells irradiated with electrons and protons," Proceedings of the 13th ICATPP Conference on Astroparticle, Particle, Space Physics and Detectors for Physics Applications, Villa Olmo (Como, Italy), 23-27 October, 2013.

[14] A. Jorio, "Effets de l'irradiation sur l'arsenure de gallium dope au slicium de type $\mathrm{n}$ : observation optique de la lacune de gallium," PHD thesis, Sherbrooke University Canada, 1995.

[15] S. Khanna, A. Jorio, C. Carlone, M. Parenteau, A. Houdayer, and J. W. Gerdes Jr. " Particle dependence of the gallium vacancy production in irradiated n-type gallium arsenide," IEEE Trans. Nucl. Sci., vol. 42, no. 6, pp. 2095-2103, Dec. 1995.

[16] O. Klein and Y. Nishina, "On the scattering of radiation by free electrons according to Dirac's new relativistic quantum dynamics," The Oskar Klein Memorial Lectures, Vol. 2: Lectures by Hans A. Bethe and Alan H. Guth with Translated Reprints by Oskar Klein, Ed. Gösta Ekspong, World Scientific Publishing Co. Pte. Ltd., Singapore, pp. 113 139, 1994.

[17] B. N. Subba Rao, "A simple formula for the transmission and absorption of monoenergetic electrons," Nucl. Instr. Meth., vol. 44, pp. 155-156, 1966.

[18] E. J. Kobetich, R. Katz, "Electron energy dissipation," Nuc. Inst. Meth., vol. 71, pp. 226-230, 1969.

[19] J. Allison, K. Amako, J. Apostolakis, and H. Araujo, "Geant4 developments and applications," IEEE Trans. Nucl. Sci., vol. 53, no. 1, pp. 270-278, 2006.

[20] GEANT4: A toolkit for the simulation of particles through matter. [online]. Available: http://geant4.web.cern.ch/geant4/ Accessed May 12, 2014.
[21] Physics Reference Manual, version GEANT4.10.1. [Online]. Available:http://geant4.web.cern.ch/geant4/UserDocumentation/UsersG uides/PhysicsReferenceManual/fo/PhysicsReferenceManual.pdf. Accessed Dec. 5, 2014.

[22] OMERE : Outil de Modélisation de l'Environnement Radiatif Externe, version 4.2. [Online]. Available:http://www.trad.fr/OMERE-14.html

[23] SR-NIEL: Screened Relativistic Nuclear Stopping Power Calculator. [Online]. http://sr-niel.mib.infn.it/index.php.

[24] A. Shatalov, S. Subramanian, and A. Klein "Correlation between nonionizing energy loss and the offset voltage shift in InP-InGaAs heterojunction bipolar transistors," IEEE Trans. Nucl. Sci., vol. 48, no. 6, pp. 2262-2269, Dec. 2001.

[25] A. L. Barry, R. Maxseiner, R. Woljik, M. Briere, and D. Braunig, "An improved displacement damage monitor," IEEE Trans. Nucl. Sci., vol. 31, no. 6, pp. 1726-1731, Dec. 1990.

[26] D. Pons, P. M. Mooney, and J. C. Bourgoin, "Energy-dependence of deep level introduction in electron-irradiated GaAs," J. Applied Phys., vol. 51, no. 6, pp. 2038-2042, April 1980.

[27] B. Lehmann, and D. Braunig, "A deep-level transient spectroscopy variation for the determination of displacement threshold energies in GaAs," J. Applied Phys., vol. 73, no. 6, pp. 2781-2785, 1993.

[28] A. Meulenberg, C. M. Dozier, W. T. Anderson, S. D. Mittleman, M. H. Zuglich, and C. E. Caefer, "Dosimetry and total dose radiation testing of GaAs devices," IEEE Trans. Nucl. Sci., vol. 34, no. 6, pp. 1745-1750, Dec. 1987.

[29] A. H. Kalma, R. A. Berger, C. J. Fischer, and B. A. Green, "Energy and temperature dependence of electron irradiation damage in GaAs," IEEE Trans. Nucl. Sci., vol. 22, no. 6, pp. 2277-2282, Dec. 1975.

[30] J. A. Grimshaw, and P. C. Banbury, "The displacement energy in GaAs," Proc. Phys. Soc., vol. 84, no. 1, pp. 151-162, Mar. 1964.

[31] P. L. Pegler, J. A. Grimshaw, and P. C. Banbury, "Electrical measurements on electron irradiated n-and p-type GaAs," Radiation effects., vol. 15, no. 3, pp. 183-193, 1972.

[32] K. Thommen, "Recovery of low temperature electron irradiationinduced damage in n-type GaAS," Radiation effects., vol. 2, no. 3, pp. 201-210, 1970 .

[33] M. Yamaguchi, C. Amano, ${ }^{60} \mathrm{Co} \gamma$-ray and electron irradiation damage of GaAs single crystals and solar cells," J. Applied Phys., vol. 54, no. 9, pp. 5021-5029, September 1983.

[34] J. H. Warner, S. R. Messenger, R. J. Walters, G. P. summers, J. R. Lorentzen, D. M. Wilt, M. A. Smith, " Correlation of electron radiation induced damage in GaAs solar cells," IEEE Trans. Nucl. Sci., vol. 53, no. 4, pp. 1988-1994, August 2006.

[35] A.L. Barry, R. Wojcik, and A.L. MacDiarmid, "Response of GaAs displacement damage monitors to protons, electrons, and gamma radiation", IEEE Trans. Nucl. Sci., Vol. 36, no. 6, pp. 2400-2404, Dec. 1989.

[36] D. V. Lang, R. A. Logan, and L. C. Kimerling, "Identification of the defect state associated with a gallium vacancy in GaAs and $\mathrm{Al}_{\mathrm{x}} \mathrm{Ga}_{1-\mathrm{x}} \mathrm{As}$," Physical Review B., vol. 15, no. 10, pp 4874-4882, May. 1977.

[37] D. Pons, A. Mircea and J. Bourgoin, "An annealing study of electron irradiation-induced defects in GaAs," J. Applied Phys., vol. 51, no. 8, pp. 4150 - 4157, September. 1980

[38] A. A. Rezazadeh and D. W. Palmer, "An electron-trapping defect level associated with the $235 \mathrm{~K}$ annealing stage in electron-irradiation nGaAs," J. Phys. C: Solid State Phys., vol. 18, no. 1, pp. 43- 54, 1985.

[39] R. Wurschum, W. Bauer, K. Maier, A. Seeger and H-E. Schaefer, "Defects in semiconductors after electron irradiation or in hightemperature thermal equilibrium, as studied by positron annihilation," Journal of Physics: Condensed Matter., vol. 1, pp. SA33- SA48, 1989.

[40] D. Pons and J. C. Bourgoin, "Irradiation-induced defects in GaAs," J. Phys. C: Solid State Phys., vol. 18, no. 20, pp. 3839-3871, 1985. 

Office National d'Études et de Recherches Aérospatiales

2 avenue Edouard Belin - BP 74025

31055 TOULOUSE Cedex 4

Tél. : +33 562252525

http://www.onera.fr 